\title{
The Canadian Engineering Education Association Research Collaboration (CEEA-RC): Annual Survey of Canadian Engineering Instructors
}

\author{
Jake Kaupp ${ }^{1}$, Sylvie Doré2, Sue Fostaty Young ${ }^{1}$ Brian Frank ${ }^{1}$, Pete Ostafichuk ${ }^{3}$, Susan McCahan ${ }^{4}$, Susan \\ Nesbit ${ }^{3}$ \\ Queen's University, École de technologie supérieure, University of British Columbia, University of Toronto \\ jake.kaupp@queensu.ca
}

\begin{abstract}
This paper will focus on the design and development of the Survey of Canadian Engineering Instructors (SCEI), from framework to final implemented version. The primary goal of this project was to increase the experience and capacity for rigorous educational research within the CEEA community, and to benchmark engineering faculty attitudes towards teaching and learning.

The development, approval and implementation of the study are a key focus presented in this paper, with the intent of providing a holistic view of how the project is managed and enacted. Alongside this narrative are the preliminary findings from the project thus far. These findings provide insight into faculty perceptions and attitudes towards teaching and learning. These responses highlight the need for a more in-depth analysis to determine the interesting trends observed in the data.
\end{abstract}

Keywords: CEEA Research Collaboration, Faculty Attitudes, Survey Design, Education Research Methods

\section{INTRODUCTION}

The growing interest in engineering education research, as well as the continued community support for the Canadian Engineering Education Association (CEEA), led to the creation of the first collaborative research project at the 2013 annual meeting in Montreal. The goals of the project are threefold:

1. Develop a community of people interested in engineering education research.

2. Develop a survey of faculty attitudes toward teaching and about their inclination to collaborate with other instructors and developers, and toward professional development.

3. Collectively model discipline-based educational research methods as part of the process (identifying research method, conceptual framework, collaborating with educational researchers, using piloting with small groups, applying for ethics approval).

At the 2013 meeting CEEA members decided that the project would be guided by a steering committee, whose members possess a background in conducting rigorous research in engineering education, and could leverage existing initiatives and resources at their institutions to provide in-kind support for the collaborative project. The steering committee would work closely with collaborators to ensure that the project captures the distinct and diverse nature of CEEA, yet the committee is responsible for the overall direction, implementation and dissemination of the research.

\section{DEVELOPMENT HISTORY}

\subsection{Initial Planning \& Phase 1}

Upon the conclusion of the 2013 meeting a call went out to all CEEA members soliciting participation, and canvassing for general research questions or areas of interest. The steering committee held initial meetings in the fall of 2013 to determine research questions, identify conceptual frameworks, define a process for collaboration with CEEA members, determine how the steering committee would work, and the overall timeline for the project.

The committee, after reviewing the feedback and community gathered from the 2013 meeting, developed the research questions to guide and focus the study, outlined below.

1. What are the current instructor attitudes about teaching and learning?

2. What are the current faculty attitudes about the role of the instructor and their duties in both the course and institution? 
3. What are the current faculty attitudes toward, and engagement in, professional development activities related to teaching?

Due to the large-scale nature of the project, the steering committee decided on using a modified Delphi process to elicit ideas from collaborators $[3,6]$. This is a well-established method to elicit the opinions of experts and professionals, and has been used for survey and instrument development for educational research [4]. below:

The modified process used in this project is outlined

1. Elicit a ranked list of proposed questions or question topics from each collaborator. These proposals must address some aspect of the research questions. Collaborators rank their own ideas from highest to lowest priority.

2. Steering committee will collect, organize, and improve consistency of the responses, and return them to collaborators for feedback to ensure the intent has been captured. The steering committee will work with an education researcher to structure the questions in a way to measure reliability of the instrument and ensure valid conclusions can be drawn from the data.

3. Steering committee will send a list of refined proposals to collaborators to be ranked, and use rankings to finalize the instrument.

The timeline for the project was agreed upon the steering committee, with the latter phases of the process allotted a greater amount of time to adjust for holidays and typical academic delays (Appendix A1).

The initial phase provided collaborators with the research questions for the project along with the underlying framework for the second construct. This framework is drawn from the work of John Biggs [2], and addresses the development of quality teaching and learning in higher education, specifically focused on the views and beliefs of the instructor towards teaching and learning. The steering committee selected this framework to address questions and priorities that emerged from the 2013 annual meeting, and to spark discussion to shape the selection and development of the frameworks underlying the first and third research questions. The identification and development of frameworks for each construct was vastly important to improve content and face validity of the survey.

\subsection{Phase 2}

The community feedback was reviewed by the steering committee and categorized according to which research question the comments or items addressed. These responses were insightful and highly valuable, with the strong themes being represented in the responses providing direction to finalize the frameworks. Suggestions for survey items were well distributed across the research questions and provided many insights into potential areas of analysis. The steering committee then divided the development effort, forming working groups to develop or refine the framework for each research question, and creating items for the draft survey. To ensure equitable work, the working group focusing on the second research question, whose framework was already identified in Phase 1, was also tasked with developing a module to collect demographic information from survey population.

\subsubsection{Survey Constructs}

Each research question naturally formed welldeveloped and rich constructs, and together they form an organizational layout and structure for the survey. Presented below are the frameworks that were selected and refined for each research question.

Construct 1: This construct focuses on general perspectives and instructor attitudes about teaching and learning,

Research Question: What are the current instructor attitudes about teaching and learning?

Framework: This construct draws upon the theories underlying the teaching perspectives inventory (TPI)[5]. The TPI focuses on five conceptual areas or modes of instruction: Transmission, Apprenticeship, Developmental, Nurturing, and Social Reform. The TPI contains questions about learning, motivation, the goals of education, role of a teacher, the nature of the learners they taught, and the influence of context on their teaching.

Construct 2: This construct focuses on the role of the instructor, their conceptions of effective teaching and learning, the roles of student and instructor, and reflective practise.

Research Question: What are the current faculty attitudes about the role of the instructor and their duties in both the course and institution?

Framework: The underlying framework for this construct was developed by John Biggs, and identifies 
three common attitudes about teaching in higher education [1]. The following descriptions of the 3 levels are a direct quote from Biggs 2001

\section{Level 1. Focus: What the student is.}

Teachers using a Level 1 theory are struck by student differences, as most beginning teachers are. They see students as easily teachable, or not. They assume a teacher-centred, transmission model of teaching. The teacher is the guardian of knowledge, whose responsibility is to know the content well, and to expound it clearly. It is then up to the student to attend lectures, to listen carefully, to take notes, to read the recommended readings, and so on. Differences in learning outcome occur because students differ in their ability, their motivation, their background, and so on. Thus, when teaching is not effective, it is seen as the students' fault. Level 1 theory does not promote reflection, whereby the teacher asks the key generative question that all expert practitioners ask: "Is my present practice the best way of doing this?"

\section{Level 2. Focus: What the teacher does.}

The Level 2 theory is also based on transmission, but of complex knowledge structures, which require skill in presenting to students, so that learning outcomes are now seen as more a function of how skillful the teacher is. Level 2 theory emphasizes what the teacher does: forward planning, good management skills, an armoury of teaching competencies, ability to use IT, and so on. Retrospective QA (quality assurance) uses Level 2 theorising when it talks about teaching competencies, and distinguished teacher awards (see below), as if focusing on what teachers do is in itself an index of student learning. In Level 2, means becomes ends.

\section{Level 3. Focus: What the student does.}

Level 3 theory focuses not on teachers, but on teaching that leads to learning. Expert teaching in this sense certainly includes mastery of teaching techniques, but unless the appropriate learning takes place, it is an empty display. Tyler, fifty years ago, said that learning "takes place through the active behavior of the student: it is what he does that he learns, not what the teacher does" (Tyler 1949, p. 63). Likewise Shuell: If students are to learn desired outcomes in a reasonably effective manner, then the teacher's fundamental task is to get students to engage in learning activities that are likely to result in their achieving those outcomes (Shuell 1986, p. 429).

Construct 3: This construct focuses on identifying what resources are available to instructors, what resources they would participate in, and potential barriers for participation in professional development related to teaching.
Research Question: What are the current faculty attitudes toward, and engagement in, professional development activities related to teaching?

Framework: Construct 3 is based on a conceptual framework for professional development adapted from Amundsen et al. that categorizes four main focal areas in faculty development: skills focus, method focus, process focus, and discipline focus [1]. The Amundsen framework was adapted for a disciplinary focus to the following framework for professional development activities. (Appendix A2)

\subsection{Phase 3}

\subsubsection{Draft Survey}

Once the frameworks were finalized, each working group created draft items for their respective construct. These items were then reviewed by the steering committee alongside educational experts in survey creation. The intent of the internal review was to streamline the draft survey prior to presenting it to collaborators at the CEEA 2014 meeting. This resulted in the removal and merging items, reallocating items to another construct, or outright removal of items that were deemed unnecessary. The survey was then created in a web-based platform, FluidSurveys, as this was the survey platform used by the host institution, Queen's University. This draft survey was packaged with a brief synopsis of the research collaboration thus far (Goals, Development, Research Questions and Frameworks) and was presented to collaborators at the 2014 annual meeting. It was at this point that the instrument was named the "Survey of Canadian Engineering Instructors" or SCEI.

\subsubsection{Ethics Approval}

In anticipation of questions from the community regarding ethics approval for the project, a draft application was created along with a combined letter of information and consent form. The draft application was completed by the steering committee and would be submitted to the General Research Ethics Board (GREB) at Queen's University upon the survey being finalized. Additionally, the steering committee consulted with the director of the Queen's Research Ethics Board (REB) for the proposed workflow for conducting collaborative national level research on this scale, shown below:

1. Steering committee applies to Queen's GREB for approval for the national study

2. Upon obtaining approval from Queen's apply to participating institutions individual REB boards, 
providing them the Queen's REB Approval, and all required supporting information

3. Once institutional approval is obtained, research can begin.

The merged letter of information and consent form was drafted according to Tri-Council Policy Statement (TCPS) and Queen's University guidelines. These documents were prepared to give collaborators at other institutions an idea of what type of information would be required in their own future. In order to meet the needs of specific institutional REBs, these draft approval documents would most likely be amended.

\subsection{Finalizing the Survey Instrument}

Immediate collaborator and community feedback was collected from the session at the conclusion of the 2014 CEEA annual meeting. Collaborators were also encouraged to take some time to consider and reflect upon the draft version of the survey, and provide their feedback to the steering committee by the end of the summer.

The majority of the feedback collected from the conference session was strongly positive and largely constituted corrections to tenses and phrasing about the instrument. This resulted in some response options being changed, as collaborators thought some of the response options could be more clearly worded. There were also some minor changes made to the demographics section of the survey, to provide better options and avenues for future analysis. These responses contributed to enhancing the face validity of the instrument, by aligning the survey items for each construct with community feedback. At the conclusion of this stage, the finalized survey along with a combined LOI and consent form constructed as a web-based instrument using FluidSurveys.

\subsubsection{Steering Committee Ethics Approval}

Upon completion of the final version of the survey, a formal application for the project was submitted to Queen's University. The project received Queen's Ethics Approval September 10, 2014; nearly a full year after the project had started. Due to the start of the academic year, the call for implementing the survey went out to collaborators on October 28th. In order to support those new to this aspect of research, and to streamline individual applications, a member of the steering committee would work with collaborators to complete their respective ethics applications. The message to collaborators presented two options to deploy the survey, with each requiring that individual institutions obtain approval from their REB prior to starting research.
1. Institutionally Hosted: Institutions host and run the survey themselves. They collect their survey data, then share a copy with the steering committee for use in the aggregate national dataset.

2. Queen's Hosted: Queen's hosts the survey, with each participating institution having its own separate collector with unique variables to highlight differences in personnel and variations in addressing REB requests. Institutions are then provided a copy of their data for their own analysis.

The typical workflow for deployment combined choosing deployment options, ethics approval, getting approval from the Dean of Engineering, contacting faculty, and surveying. For clarity, it is shown below:

1. Select deployment strategy

2. Contact ethics board to determine application type

3. Work with steering committee member to obtain ethics approval

4. Contact the Dean of Engineering to inform them and obtain approval

5. Contact the faculty members to invite them to participate

6. Schedule a reminder email for a later date

Institutional deployments started in late November of 2014, working towards obtaining institutional ethics approval. The survey started to go live in January 2015. The steering committee decided to let each institution set its own timeline, as many collaborators wished to coincide the deployment of the survey with specific events, or to adapt to unforeseen consequences.

\subsection{Current Status}

As of writing this paper, there have been 10 different institutions that have been involved with the project thus far. The survey has launched and completed at 8 of those institutions, one of those institutions is waiting to contact faculty at the conclusion of the academic year, and one institution is just beginning the ethics approval process.

The steering committee expects that following the presentation of this paper, there may be more institutions wanting to participate in the project. To accommodate those yet to survey their faculty, and to accommodate potential newcomers we are keeping the project open until September 2015, which coincides with the ethics renewal for the project. 


\section{RESULTS}

The results presented in this paper are a presentation of summary statistics and general observations regarding constructs and items. This interim report utilizes all survey responses collected up until April 15th, 2015. A more thorough analysis of the survey and the results will be conducted in the future, upon the conclusion of data collection.

\subsection{Demographics}

The response for the survey was quite positive, illustrated below in table 1 .

Table 1: Summary response statistics

\begin{tabular}{rrr} 
Responses & Institutions & Avg.Time (mins) \\
\hline 164 & 8 & 15.44
\end{tabular}

Out of 22 institutions that expressed interest in the research collaboration, only 8 have implemented the survey. At the April 15th cutoff point, two institutions were in the process of approval or implementation. When faculty counts are obtained for each institution, a true response rate can be generated. Respondents took an average time of 15.44 minutes to complete the survey, which is under the anecdotal 20 minute heuristic to maintain survey engagement.

The distribution of instructor classification, shown below in table 2 , illustrates that respondents were mostly classified as a traditional professor. Those who responded "other", show a mix of emeritus professors, administrators and specialized staff shown in table 3 .

Table 2: Distribution of Instructor Classification

\begin{tabular}{lr} 
Academic Title & Frequency \\
\hline Other, please specify... & 7 \\
Sessional/adjunct professor or lecturer & 9 \\
Teaching stream professor or lecturer & 15 \\
Traditional professor (balance of scientific & 133 \\
research \& teaching) &
\end{tabular}

Table 3: Other Roles

Academic Title

Administrator with teaching \& research $\quad 2$

responsibilities

Ancillary Academic Staff - Learning 1

Specialist

Professor Emeritus

Research assistant professor

Senior Administrator

CEEA15; Paper 15

McMaster University; May 31 - June 3, 2015
The majority of the population had 7-15 years of teaching experience, with a relatively even distribution in the remaining experience categories, shown below in table 4.

Table 4: Teaching Experience

Teaching Experience Frequency

$\begin{array}{ll}0-6 \text { years } & 34 \\ 7-15 \text { years } & 66 \\ 16-25 \text { years } & 33 \\ >25 \text { years } & 31\end{array}$

The majority of the population was focused largely on undergraduate teaching, reporting that teaching occupies approximately $21-60 \%$ of faculty work time, illustrated below in table 5 .

Table 5: Teaching Focus and Division of Work Time

\begin{tabular}{rrr} 
Percentage & $\begin{array}{r}\text { Undergrad vs. } \\
\text { Graduate Teaching } \\
\text { (Frequency) }\end{array}$ & $\begin{array}{r}\text { Average teaching } \\
\text { time per year } \\
\text { (Frequency) }\end{array}$ \\
\hline $0-20 \%$ & 5 & 11 \\
$21-40 \%$ & 4 & 66 \\
$41-60 \%$ & 25 & 64 \\
$61-80 \%$ & 73 & 19 \\
$81-100 \%$ & 56 & 4
\end{tabular}

\subsection{Construct 1: General Perspectives and Attitudes}

The majority of survey respondents would classify themselves as enjoying teaching to a great or fairly great extent, as illustrated in figure 1 below.

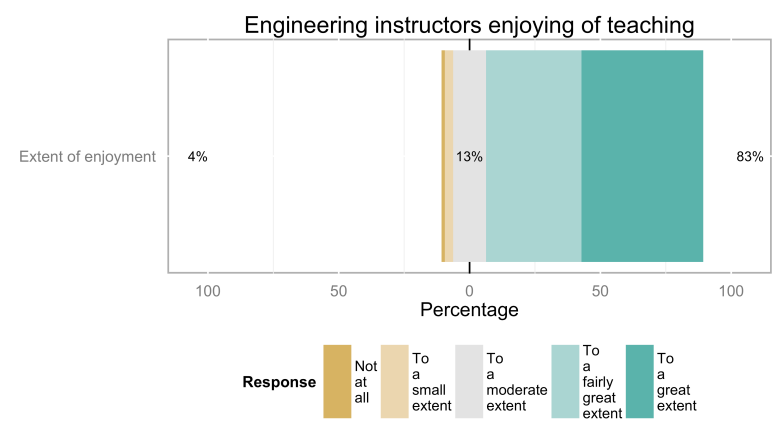

Figure 1: Engineering instructors enjoyment of teaching

The top teaching goals of survey respondents were transmission of information $\left(76 \%, 1^{\text {st }}\right.$ or $2^{\text {nd }}$ priority), adopting a learner-centered development of understanding and facilitating construction of meaning $\left(60 \%, 1^{\text {st }}\right.$ or $2^{\text {nd }}$ priority). Nurturing students to reach their personal potential was third $\left(35 \%, 1^{\text {st }}\right.$ or $2^{\text {nd }}$ priority) with a 
relatively even split between high and low priority. The lowest priorities were social change through education of the next generation of engineers $(73 \%$ ranked lowest priority), apprenticeship by socializing students into the practice of engineering ( $55 \%$ ranked lowest priority).

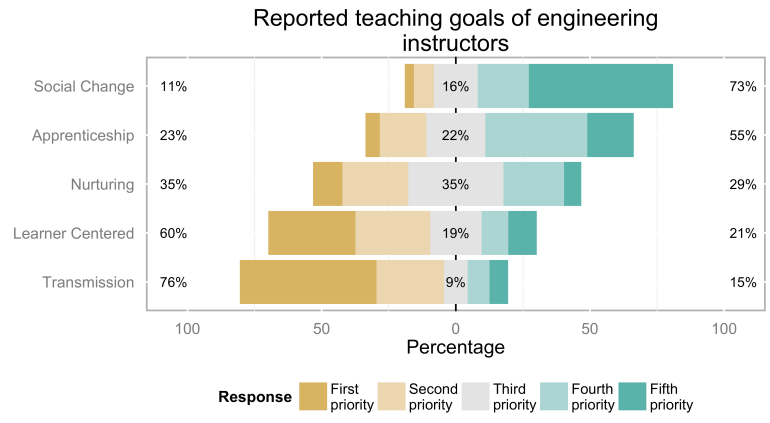

Figure 2: Reported teaching goals of engineering instructors

The primary influences of survey respondents to make changes in their teaching are outlined below in figure 3. Personal observation from previous teaching $(92 \%)$ and course evaluations $(63 \%)$ were the most influential, with professional development $(31 \%)$, literature on teaching and learning $(29 \%)$ and input from colleagues being indicated as being less influential.

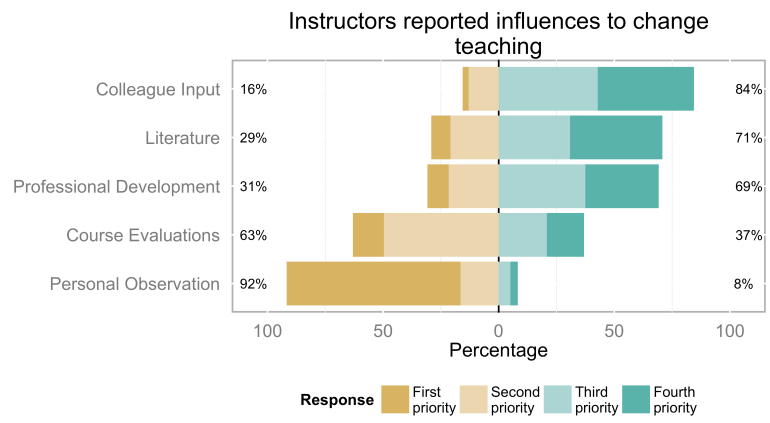

Figure 3: Reported influences to change teaching

Survey respondents indicated that, when they are dissatisfied with student learning in their course, they believe that the top three reasons are: student workload, inadequate learning skills and underprepared or unmotivated students. There were very few responses that indicated teaching, resources or curriculum as a potential factor.
Table 6: Instructor perceptions of common problems when dissatisfied with student learning

Reason

Frequency

Underprepared Students $\quad 57$

Under motivated Students $\quad 52$

Inadequate Learning Skills $\quad 67$

Student Workload 83

Poor Curriculum Design $\quad 25$

Excessive Course Content Curriculum 23

Excessive Course Content Instructor 26

Inadequate Resources $\quad 26$

Inability Assessing Feedback $\quad 21$

Inadequate Teaching $\quad 30$

Poor Student Engagement 43

Poor Course Administration 0

Poor Classroom Management 2

\subsection{Construct 2: Attitudes About the Role and Duties an Instructor}

When asked a series of questions to determine the roles and duties of instructors, survey respondents overwhelmingly indicated that the primary responsibility of an instructor was to motivate students to learn, provide them with a clear explanation of what it is they are expected to learn, and provide learning opportunities in which they can deeply engage $(61 \%)$. The other two categories were difficult to discern, with content knowledge and articulation and knowledge and application of best teaching practices being more evenly split in rankings, as illustrated below in figure 4 .

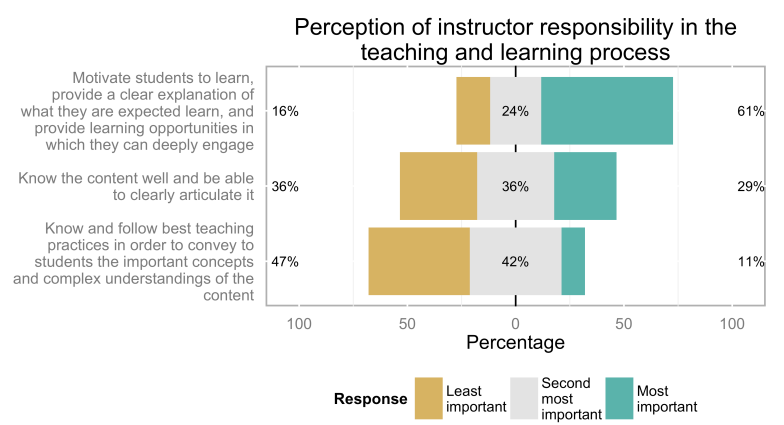

Figure 4: Perception of instructor responsibility in the teaching and learning process 
Instructor perceptions of student responsibilities in teaching and learning show that the majority of survey respondents agree that the student is responsible for knowledge and motivation (54\%), as well as 'doing the work' (48\%). Nearly all respondents indicated that students share the responsibility in teaching and learning, ranking the statement "If the student has the ability to do the work, he or she doesn't really need to take on any added responsibility" last (Figure 5).

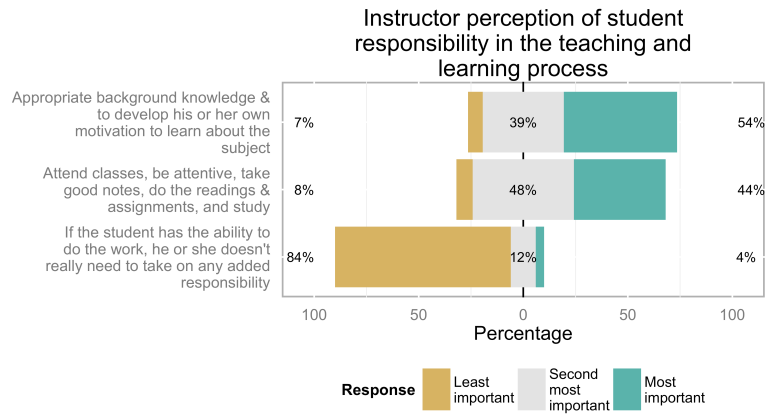

Figure 5: Instructor perception of student responsibility in the teaching and learning process

Interestingly, instructor perceptions of how to positively influence student success identify a teacherfocused theme, illustrated in figure 6 . Effective presentation, classroom management and engaging learning opportunities was ranked as most important $(56 \%)$, with the other two choices of content mastery and clear articulation and teaching and assessment methods supporting outcomes being virtually indistinguishable.

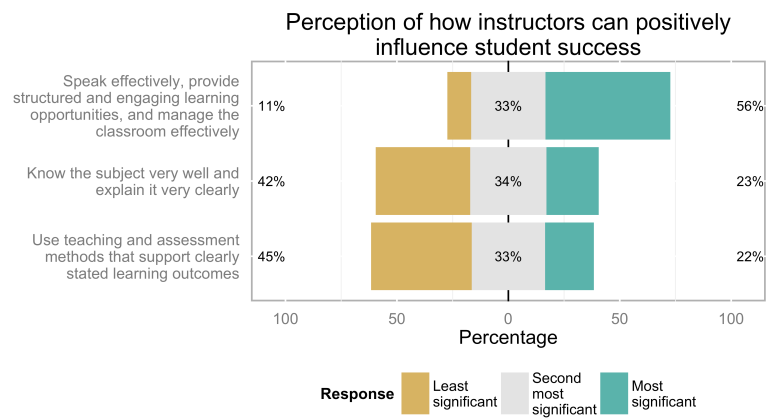

Figure 6: Perception of how instructors can positively influence student success

Nearly all respondents identified themselves as both a knowledge and teaching expert in their area of specialization (Figure 7).

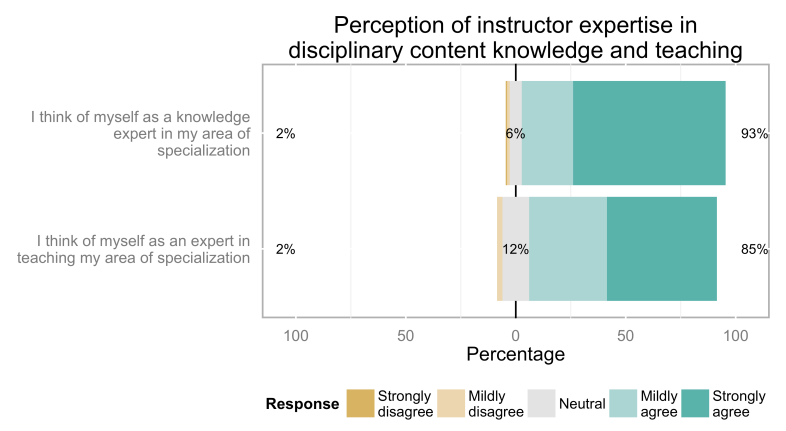

Figure 7: Perception of instructor expertise in disciplinary content knowledge and teaching

Nearly all respondents responded that they primarily use student course and teaching evaluations to improve delivery (68 responses). Other uses of student evaluations were spread relatively equal across other categories, with only a very small minority (4 responses) not reviewing course evaluations.

Table 7: Perception of important uses of student course and teaching evaluations

Action Frequency

I look at the quantitative results (i.e. 26 numerical ratings) to see if students felt the course and my teaching were effective.

I look for clues as to how well students understood the intended learning outcomes, and if the students agreed that the learning assessments aligned with these outcomes. I look for ideas on what approaches might improve my delivery of the material.

I look to see if students have found lectures or learning activities to be unclear or confusing.

I usually do not review student evaluations.

The student evaluations at my institution do not provide meaningful results I can use in my teaching practice.

\subsection{Construct 3: Attitudes Towards and Engagement in Professional Development}

Nearly all categories for professional development were ranked as important for engineering educators (Figure 8). Teaching processes (curriculum development, program improvement), teaching skills and teaching assessment methods were virtually the same, but scholarship was the item that produced the most diversity in responses. 


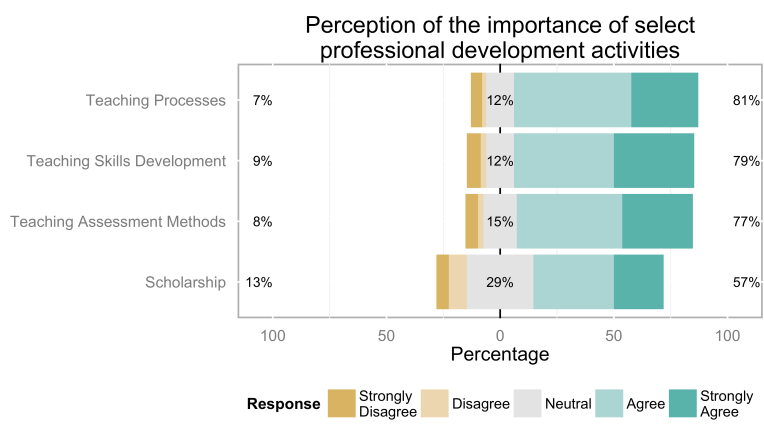

Figure 8: Perception of the importance of select professional development activities.

In light of the previous question, participation in professional development activities echoes the ranking of importance. What is surprising is that this trend is reversed in the awareness of support for professional development activities, with the awareness of support for scholarship being the highest rated (68\%).

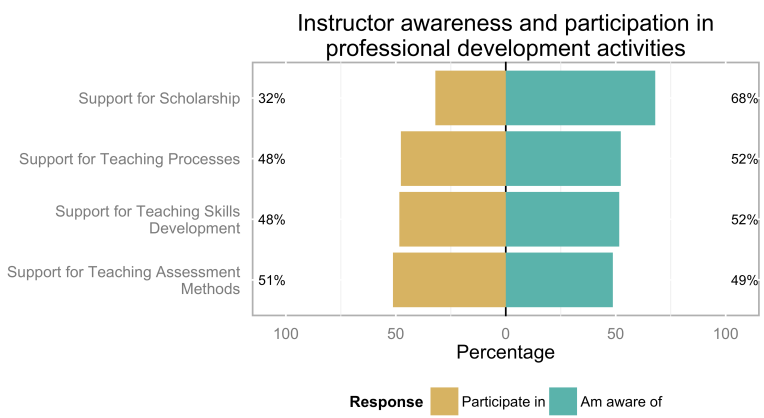

Figure 9: Instructor awareness and participation in professional development activities

Within the past five years respondent participation in teaching professional development was mainly participation in 1: small 1-2 hour seminars (116 responses), 2: independent learning (112 responses) and 3: 3 hour to full day workshops on teaching (90 responses).
Table 8: Instructor participation in faculty development activities in the past 5 years.

Activity

Attended a seminar on teaching (1-2 hours

Frequency

of professional development)

Participated in a workshop on teaching (3

hours to a full day of professional

development)

Participated in a multi-day workshop on

teaching (several day professional

development activity)

Participated in conference related to

education (either disciplinary or not)

Learning independently through reading, etc.

Led workshops focusing on teaching and

learning development

Internal university funding to support

course or program development

External funding to support course or program development

Internal university grants supporting

educational research

External grants supporting educational

research

The ranking of obstacles to participation in professional development activities are illustrated below in figure 10. The two greatest obstacles indicated by respondents were workload (91\%) and the timing of the event $(84 \%)$. The two least significant obstacles were the lack of access to funding (47\%), and the lack of access to expertise (85\%).

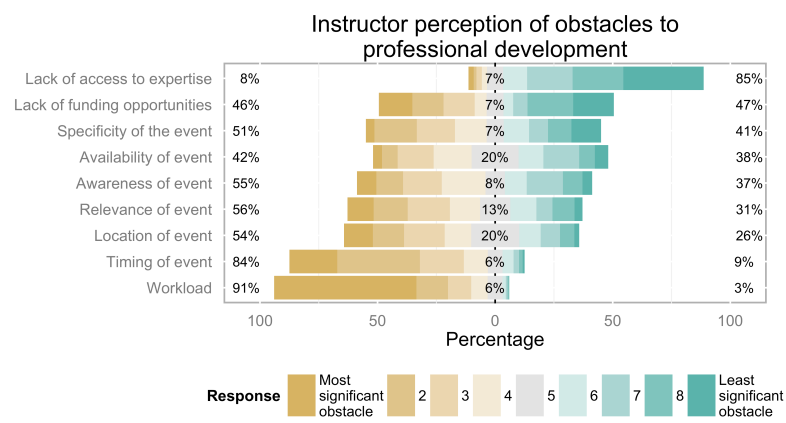

Figure 10: Instructor perception of obstacles to professional development

Compared to table 8 , the responses illustrated in figure 10 suggest that the majority of instructor participation in professional development is skewed towards non-teaching focused activities. There were 89 responses that responded that $0-40 \%$ of their professional development activities in the past 5 years were teaching-focused, which accounts for approximately $54 \%$ of the population. 
Table 9: Percentage of teaching-focused professional development activities attended in the past five years

\begin{tabular}{rr} 
Percentage & Frequency \\
\hline $0-20 \%$ & 57 \\
$21-40 \%$ & 32 \\
$41-60 \%$ & 25 \\
$61-80 \%$ & 24 \\
$81-100 \%$ & 21
\end{tabular}

Nearly all respondents indicated that professional development, as training for new faculty was needed across all areas. Yet the order of these areas differs from the figure 9. The perception is that new faculty should be trained in assessment and teaching skills first, with teaching processes and scholarship being of lesser importance.

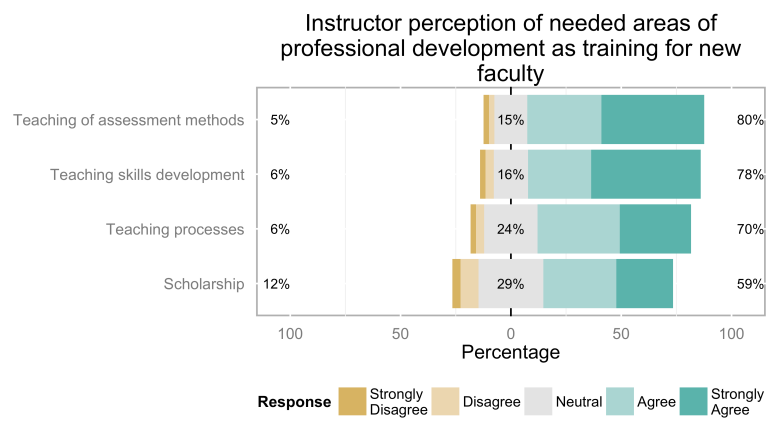

Figure 11: Instructor perception of needed areas of professional development as training for new faculty.

This trend also held true in the second part of the question pertaining to professional development as continuing education for experienced faculty. Interestingly, there was a lower level of agreement regarding this question compared to the responses for training for new faculty.

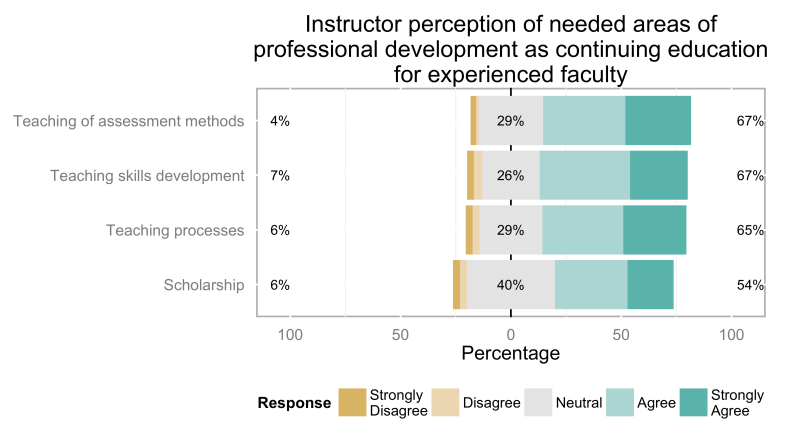

Figure 12: Instructor perception of needed areas of professional development as continuing education for experienced faculty
Survey respondents were split on whether or not professional development activities were taken into account during annual performance review. The majority (70 responses) indicated that, yes, professional development activities were taken into account. A large number of respondents were unsure if professional development was used (64) and very few answered that, no, professional development activities were not taken into account. This highlights the potential need for further clarification of the benefit and impact of professional development activities beyond the individual.

Table 10: Percentage of teaching-focused professional development activities attended in the past five years

\begin{tabular}{lr} 
Percentage & Frequency \\
\hline Yes & 70 \\
No & 30 \\
Unsure & 64
\end{tabular}

\section{Conclusions}

The results from this initial sample of responses have highlighted some interesting avenues for analysis and future investigation. The initial results were from the scale items alone, and did not include any of the openresponse items. The reason for this was time-based, as qualitative analysis of these responses takes considerable time.

The next steps for the research collaboration are to complete the implementation of the survey at the remaining institutions, and include any additional institutions that have yet to participate. Once data collection has concluded, a paper is planned to address the development and validation of the instrument along with the report on the complete national dataset. Future analysis includes establishing reliability measures for scales and constructs, cross-tabulation by various factors and demographics, and qualitative analysis of open-text responses. More immediate concerns are the timeline for dissemination of institutional data and the aggregate national dataset, and the long-term management, collection and reporting on the data.

Even in its infancy, this instrument and approach has garnered attention from colleagues outside of engineering and the steering committee has received positive feedback about the impact of this project and its importance. This highlights a need for the continued use, development and improvement of the instrument, as well as a effort to move the CEEA research collaboration into the next phase. 
In the interest of conducting open and collaborative research, nearly all collection, analysis, writing and report generation was done using open-source or readily available technologies. These include Google Drive, R, RStudio, Github, and Atom. This report was written in rMarkdown in RStudio, typset using Knitr \& pandoc and hosted at Gitub. You can view this report, the code that created and associated analysis at http://github.com/jkaupp/R-SCEI

\section{Acknowledgements}

The steering committee would like to thank the CEEA for its support and assistance in conducting this project.

\section{References}

[1] Amundsen, C, Philip C Abrami, L McAlpine, C Weston, M Krbavac, A Mundy, and M Wilson. 2005. "The what and why of faculty development in higher education: An in-depth review of the literature." In American Education Research Association Annual Meeting. Montreal.

[2] Biggs, John. 2001. "The Reflective Institution: Assuring and Enhancing the Quality of Teaching and Learning." Higher Education 41 (3). Springer: 22138.

[3] Brown, Bernice B. 1968. "Delphi Process: a Methodology Used for the Elicitation of Opinions of Experts," September.

[4] Facione, P A. 1990. "The delphi report." Committee on Pre-College Philosophy. American Philosophical Association.

[5] Pratt, D D, and J B Collins. 2000. "The teaching perspectives inventory (TPI)." Adult Education Research Conference.

[6] Sackman, H. 1974. "Delphi assessment: Expert opinion, forecasting, and group process." 


\section{Appendix A1: Project Timeline}

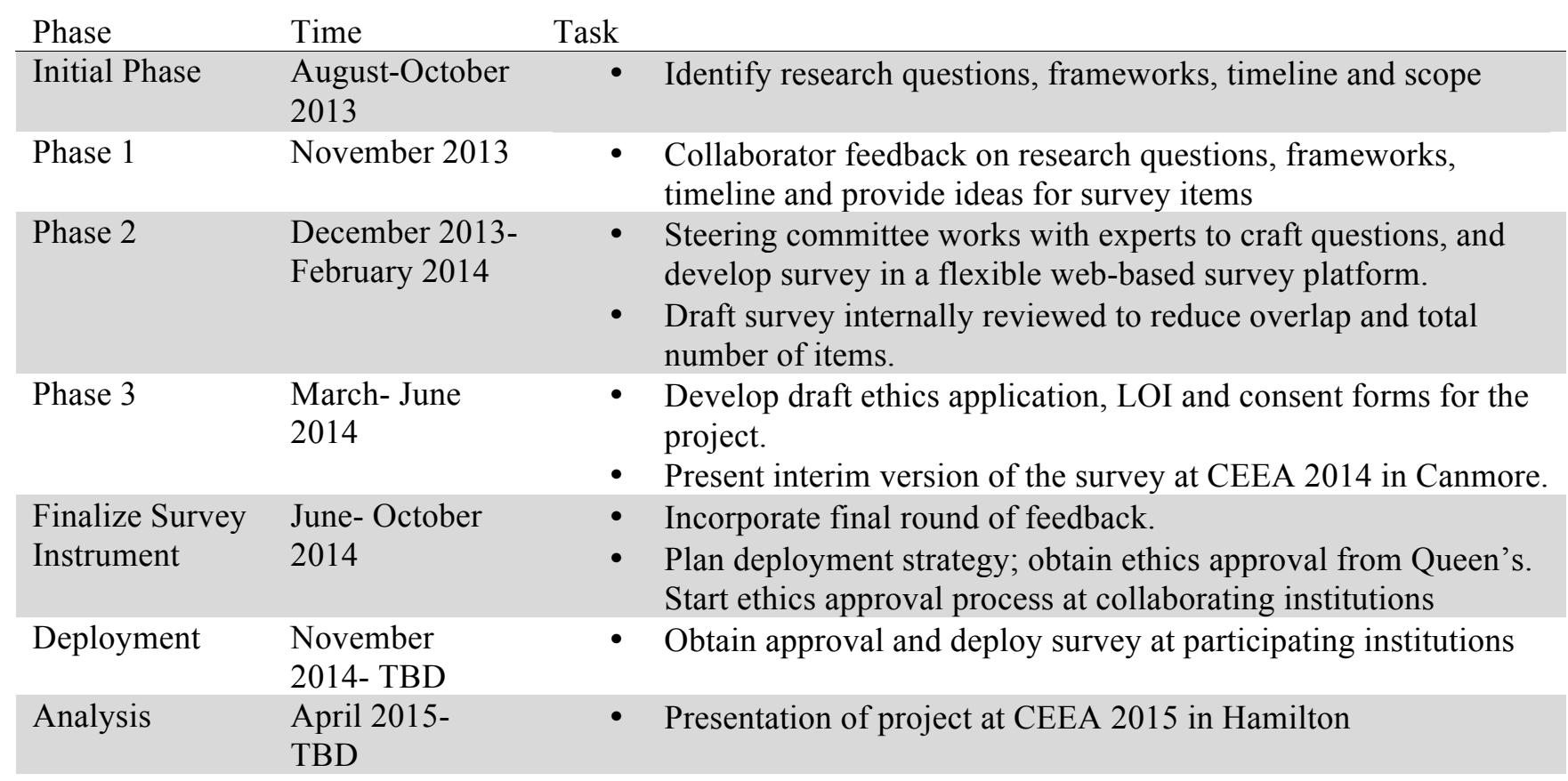




\section{Appendix A2: Modified Abrami Framework underlying construct 3}

\begin{tabular}{|c|c|c|}
\hline Categories & Disciplinary Focus & Multidisciplinary Focus \\
\hline $\begin{array}{l}\text { Skills } \\
\text { (presentations, } \\
\text { discussion } \\
\text { facilitation, } \\
\text { learning } \\
\text { technology) }\end{array}$ & $\begin{array}{l}\text { Training on using engineering } \\
\text { hardware/software in courses. } \\
\text { Personal reading on using engineering } \\
\text { hardware/software in courses. }\end{array}$ & $\begin{array}{l}\text { Training on using general } \\
\text { educational software/hardware } \\
\text { (learning management systems, } \\
\text { clickers, etc.) } \\
\text { Personal reading on general } \\
\text { education hardware/software in } \\
\text { courses (learning management } \\
\text { systems, clickers, etc.) } \\
\text { Training on organization, } \\
\text { presentations, writing on a } \\
\text { blackboard, etc. }\end{array}$ \\
\hline $\begin{array}{l}\text { Teaching } \\
\text { methods } \\
\text { (project-based } \\
\text { learning, case } \\
\text { studies, active } \\
\text { learning, etc.) }\end{array}$ & $\begin{array}{l}\text { Workshops/training on teaching } \\
\text { methods specific to engineering } \\
\text { (education sessions at disciplinary } \\
\text { conferences, workshops on teaching } \\
\text { design, engineering labs, etc.) } \\
\text { Personal reading on teaching methods } \\
\text { specific to engineering (education } \\
\text { sessions at disciplinary conferences, } \\
\text { workshops on teaching design, } \\
\text { engineering labs, etc.) }\end{array}$ & $\begin{array}{l}\text { Workshops/training on general } \\
\text { teaching methods (active learning, } \\
\text { service learning, collaborative } \\
\text { learning, etc.) } \\
\text { - Personal reading on general } \\
\text { teaching methods (active learning, } \\
\text { service learning, collaborative } \\
\text { learning, etc.) }\end{array}$ \\
\hline $\begin{array}{l}\text { Processes and } \\
\text { critical } \\
\text { analysis }\end{array}$ & $\begin{array}{l}\text { Workshops/sessions on teaching and } \\
\text { learning processes specific to } \\
\text { engineering (course redevelopment } \\
\text { workshops, curriculum design, } \\
\text { assessment, graduate attributes) } \\
\text { Facilitated sessions on working } \\
\text { collaboratively as an engineering } \\
\text { department on curriculum design, } \\
\text { assessment, etc. Broad informal } \\
\text { holistic discussions on teaching and } \\
\text { learning issues with colleagues }\end{array}$ & $\begin{array}{l}\text { Workshop/session on general } \\
\text { teaching and learning processes } \\
\text { (constructive alignment, } \\
\text { curriculum design, assessment, } \\
\text { etc.) } \\
\text { Facilitated sessions on curriculum } \\
\text { design, assessment, learning } \\
\text { science, etc. }\end{array}$ \\
\hline $\begin{array}{l}\text { Personal } \\
\text { scholarship }\end{array}$ & $\begin{array}{l}\text { - Presenting and seeking feedback to } \\
\text { engineering colleagues on teaching and } \\
\text { learning innovations Scholarly work } \\
\text { related to engineering education }\end{array}$ & $\begin{array}{l}\text { - Presenting to and seeking feedback } \\
\text { from a range of disciplines } \\
\text { Scholarly work related to teaching } \\
\text { and learning }\end{array}$ \\
\hline
\end{tabular}

